\title{
As relações do poder segundo Michel Foucault e Byung-Chul Han: uma proposta de articulação para a análise da complexidade do poder local em Moçambique d
}

\section{Power relations according to Michel Foucault and Byung-Chul Han: an articulation proposal for the analysis of the complexity of local power in Mozambique}

\author{
Jochua Abrão Baloi \\ Doutorando em Ciências Política (UERJ) \\ Universidade São Tomás de Moçambique (USTM) \\ Maputo, Moçambique \\ E-mail: jbaloi@yahoo.com.br
}

Resumo: O objetivo deste artigo é analisar as relações do poder em Michel Foucault e Byung-Chul Han para a compreensão da complexidade do poder local em Moçambique. Nele argumenta-se que as concepções de poder em Foucault e em Han são importantes não só para a formação e constituição das atuais teorias de poder, como também para compreender a complexidade do poder local no Estado moderno que se presa democrático. Esta premissa é secundada pelas concepções de poder avançadas por estes teóricos, ao afirmarem, por um lado que o poder é um fenômeno que ocorre numa relação assimétrica bipolar, que institui a autoridade e a obediência (Foucault) e, por outro lado, que o poder é um fenômeno de continuidade, onde a vontade do eu pode-se expandir e continuar no outro (Han). A partir de uma metodologia de análise bibliográfica, histórica e do process tracing, aliando-os ao hermenêutico-reflexivo, este artigo buscou compreender a complexidade do poder local em Moçambique considerando as lições dadas por Foucault e Han. Com este artigo conclui-se que as concepções de poder tanto em Foucault, como em Han são deveras importantes para compreender as atuais teorias de poder, e não só, como também para entender quão complexa é a concepção do poder local nos Estados que se queiram democráticos, e que Moçambique não constitui exceção.

Palavras-chave: Poder. Poder Local. Foucault. Han.

Abstract: This article comes about with the objective of analyzing the power relations in Michel Foucault and Byung-Chul Han to understand the complexity of local power in Mozambique. It argues that Foucault and Han's conceptions of power are important not only for the formation and constitution of current theories of power, but also for understanding the complexity of local power in the modern democratic states. This premise is supported by the conceptions of power advanced by these theorists, where, on one hand, power is a phenomenon that occurs in a bipolar asymmetric relationship, which establishes authority and obedience (Foucault) and, on the other hand, power is a phenomenon of continuity, where the will of the self can expand and continue on the other (Han). Based on a bibliographic, historical and process tracing analysis methodology, combining them with the hermeneutic-reflexive method, this article sought to understand the complexity of local power in Mozambique considering the lessons given by Foucault and Han. This article concludes that the conceptions of power in both Foucault and Han are very important to understand not only the current theories of power, but also to understand how complex the conception of local power is in the democratic states, and that Mozambique is not exception.

Keywords: Power. Local Power. Foucault. Han. 


\section{Introdução}

O presente artigo põe em pauta a análise das relações do poder em Michel Foucault e Byung-Chul Han para a compreensão da complexidade do poder local em Moçambique. Na prática, busca compreender as ideias lançadas por estes dois teóricos na procura duma percepção do que venha a ser o poder e a importância deste na formação e constituição das teorias atuais do poder em Estados que se presam democráticos.

Destarte, o argumento central que norteia artigo é que, as concepções de poder em Foucault e em Han são importantes não só para a formação e constituição das atuais teorias de poder, como também para compreender a complexidade do poder local em Moçambique, uma vez que para eles o poder é um fenômeno social.

Este artigo mostra ainda, que Michel Foucault definitivamente rompe com a concepção clássica do poder, que o pensava na pessoa de quem o detém, que o exerce e que o mantém, quer dizer, era atribuído a uma pessoa ou a um grupo de pessoas que exercia um certo domínio sobre os outros. Foucault, portanto, pensa o poder como uma rede de relações onde todos os indivíduos estão envolvidos, como geradores ou receptores, dando vida e movimento a essas relações.

É neste sentido que Foucault define o poder como uma relação assimétrica que institui a autoridade e a obediência, e não como um objeto preexistente num soberano, que o usa para dominar seus súbditos. A bem dizer, para ele, o poder acontece como uma relação de forças, onde ele apresenta a vigilância e a punição como dois dispositivos que a sociedade usa para justificar não só o poder, como também para domesticar os corpos que constituem o tecido social.

No mesmo diapasão, Byung-Chul Han concebe o poder como capacidade que o Eu (Ego) tem de continuar a sua relação no Outro (Alter), no sentido de que ambos se ligam através duma relação de liberdade com um carácter comunicacional.

Entretanto, para Han, para que haja o poder é preciso que existam sujeitos livres ligados por uma continuidade de relações onde há aceitação de vontades entre os sujeitos implicados nesta relação. À vista disso, a continuidade e a mediação comunicativa são elementos fundantes do poder em Han.

A questão principal que norteia este artigo é: qual é a relevância das relações do poder em Michel Foucault e Byung-Chul Han para a compreensão da complexidade do poder local em Moçambique?

A partir de uma metodologia de análise bibliográfica, histórica e do process tracing, aliando-os ao hermenêutico-reflexivo, este artigo buscou compreender a complexidade do poder local em Moçambique considerando as lições dadas por Foucault e Han.

Este artigo está dividido em quatro partes: A primeira parte apresenta uma abordagem teórica sobre uma relação possível entre a concepção de poder em Foucault e em Han. Em seguida debate uma articulação possível e necessária entre os seus ideais de poder, apresentando as similitudes e as diferenças neles adjacentes. Depois analisa a contribuição do pensamento destes dois teóricos nas teorias atuais do poder e por fim, discute a relevância das concepções destes teóricos na compreensão da complexidade do poder local em Moçambique. 


\section{0 poder na concepção de Michel Foucault e Byung-Chul Han: uma relação possível?}

Existem várias abordagens sobre a problemática do poder, tanto na teoria e filosofia política como no direito, contudo a abordagem do poder que se pretende neste artigo está ligado ao poder que é pensado sob o ponto de vista do espaço social. Os teóricos como Habermas (1976), Bourdieu (2001), Weber (2004), Arendt (2010), Foucault (1979), Han (2019), entre outros discutem as relações do poder, contudo, neste artigo interessa de forma mais específica analisar a concepção do poder nos dois últimos.

Michel Foucault (1926-1984) foi um filósofo, historiador e sociólogo francês e que no seu pensamento, um dos temas que aborda é o poder. Ele concebe o poder como uma relação assimétrica entre a autoridade e obediência e nunca um objeto preexistente na pessoa do soberano que o usa para dominar os seus súbditos.

Partindo desta concepção do poder relacional, Foucault pensa o poder numa relação assimétrica bipolar cuja natureza é a subordinação e manutenção da ordem política, quer dizer, por um lado temos quem o exerce e, por outro lado temos o objeto deste poder.

Apesar de muitos teóricos referirem-se sobre a existência de uma teoria de poder em Foucault, estudos mais aprofundados negam a existência de uma teoria de poder per si, com a justificativa de que o poder não existe como realidade, posto que, não possui uma essência passível de ser definida, mas sim existe um conjunto de forças distintas, que estão em constante mutação (FOUCAULT, 1979).

No mesmo contexto de não existência de uma teoria de poder em Foucault, Revel $(2005$, p. 67) alega que Foucault:

nunca trata do poder como uma entidade coerente, unitária e estável, mas de relações de poder que supõe condições históricas de emergência complexas e que implicam efeitos múltiplos, compreendidos fora do que a análise filosófica identifica tradicionalmente como o campo do poder.

Esta citação leva à dedução de que em Foucault, o poder não é objeto passível de ser apreendido como na teoria de conhecimento de Kant ${ }^{1}$, mas sim como uma prática social que é historicamente construída. Por isso, para ele, rigorosamente falando, o poder como tal não existe, mas sim, relações do poder.

Neste sentido, para entender em que consiste o poder em Foucault é necessário a priori perceber os conceitos que se aproximam e compõem esta concepção do poder e também as relações que distinguem do que não poderia ser considerado poder.

No geral, e no concernente ao objeto deste artigo,

o poder é um conjunto de relações; em vez de derivar de uma superioridade, o poder produz a assimetria; em vez de se exercer de forma intermitente, ele se exerce permanentemente; em vez de agir de cima para baixo, submetendo, ele se irradia de baixo para cima, sustentando as instâncias de autoridade; em vez de esmagar e confiscar, ele incentiva e faz produzir (ALBUQUERQUE, 1995, p. 109).

${ }^{1}$ Cfr. Para entender sobre a Teoria de Conhecimento de Kant pode-se consultar a seguinte obra: KANT, I. (1987). Crítica da Razão Pura. Os pensadores Vol. I. São Paulo: Nova Cultural. 
Esta citação faz perceber que na noção relacional do poder em Foucault não existe definitivamente a Vontade Política (Hobbes ${ }^{2}$ ), no sentido de que não existe transferência do poder político exercido pela autoridade, onde cada um submete a sua vontade à de um outro (eleito) que seja único ou que esta vontade única seja considerada como a Vontade Geral (Rousseau $\left.{ }^{3}\right)$.

A crítica que Foucault faz à percepção moderna do poder é que o poder não carregue unicamente tendências repressivas, posto que para ele, a

noção de repressão é totalmente inadequada para dar conta do que existe justamente do produtor no poder. Quando se define os efeitos de poder para repressão, tem-se uma concepção puramente jurídica deste mesmo poder; identifica-se poder a uma lei que diz não. O fundamental seria a força de proibição. Ora, creio ser esta uma noção negativa, estreita e esquelética do poder que curiosamente todo mundo aceitou (FOUCAULT, 1998, p. 8).

Neste contexto, pode-se inferir que para Foucault, as relações do poder disciplinar são essenciais por não se considerarem uma relação negativa, mas sim positiva, no sentido de que é produtor da individualidade, ou seja, o indivíduo é um produto/ produção do poder e do saber, isto é, o indivíduo não é algo exterior ao poder.

Foucault na sua obra "Vigiar e Punir" inaugura a noção do poder disciplinar, situando-a numa relação de enclausuramento. Portanto, nesse tipo específico de relação, o corpo dos sujeitos era investido de tecnologias de poder e controle, mas essa tecnologia, ao contrário do que possa sugerir, não era exclusiva da prisão (FOUCAULT, 2014).

Relativamente às formas de funcionamento ou às formas do exercício do poder, Foucault refere à três elementos. O primeiro é o poder soberano, o segundo é o poder disciplinar e o terceiro é a biopolítica.

O poder soberano em conformidade com Foucault ficou situado num período histórico antes da concepção do biopoder, onde se associa ao poder de matar, onde existe alguém com poderes superiores que os outros, sem nenhum espaço de intermediação.

O poder disciplinar está ligado ao poder sobre os indivíduos nas sociedades fechadas, próprias da sociedade moderna, como na clausura, nas escolas, nos hospícios, nas fábricas, etc., que possuem suas regras e mecanismos próprios para melhorar o rendimento do corpo social, utilizando a tecnologia própria de controlo e obediência. Em "Vigiar e Punir", Foucault considera 4 características fundamentais do poder disciplinar (FOUCAULT, 2014).

A primeira caraterística refere que a disciplina é um tipo de (re)organização do espaço, quer dizer "é uma técnica de distribuição dos indivíduos através da inserção dos corpos em um espaço individualizado" (Dreyfus \& Rabinow, 1995, p. XVII), no sentido de que deixa de pertencer exclusivamente a um dispositivo central como o Estado e está presente em todas as demais instituições existentes na sociedade.

\footnotetext{
${ }^{2}$ Cfr. Para entender sobre a Vontade Política pode-se consultar a seguinte obra: HOBBES, T. (2002). Do Cidadão. (Coleção Clássicos). Trad. Renato Janine Ribeiro. São Paulo: Martins Fontes.

${ }^{3}$ Cfr. Para entender sobre a Vontade Geral pode-se consultar a seguinte obra: ROUSSEAU, J.J. (2000). Do Contrato Social. São Paulo: Nova Cultural.
} 
A segunda característica aduz que a disciplina serve como um controle de tempo, ou seja, a disciplina torna o corpo ágil e hábil para qualquer que seja a atividade. Neste sentido, "o controle do tempo compreende uma dupla articulação, constituída pela relação entre corpo e gesto - um corpo capaz de executar de forma ágil e eficaz um gesto - e a relação gesto e objeto manipulado pelo corpo" (SOUZA, 2011, p. 114).

A terceira caraterística atesta que a disciplina serve como vigilância, no sentido de que, ela deve ser exercida "de forma contínua, ininterrupta, permanente, ilimitada" (Souza, 2011, p. 114), quer dizer, deve ser exercida de forma total. Sendo assim, a vigilância é um dos principais métodos de controlo, que deve ser exercida de forma constante, sem limites, que penetre nos âmbitos mais particulares da vida dos indivíduos e que esteja presente em todo lugar.

A quarta e última caraterística afirma que a disciplina produz um saber, pois constitui um registo contínuo de reconhecimento. Deste modo, para Foucault, a disciplina "regista e transfere (aos pontos hierarquicamente mais altos do poder) aquilo que é objeto dessa vigilância, desse olhar" (SOUZA, 2011, p.114).

A biopolítica como a terceira forma de funcionamento ou do exercício do poder, é considerada em Foucault, como uma compreensão da sociedade em termos do corpo sobre o qual se exerce um poder de controlo, e Foucault considera que o poder sobre a vida é o centro da biopolítica que se exerce em duas direções, uma que se centra no corpo individual como máquina, onde nele deve-se submeter à disciplina para aumentar as suas aptidões para ganhar a eficácia e a outra é o controlo do corpo da população como uma espécie de mecanismos de regulação (FOUCAULT, 2010).

A respeito da colocação dos argumentos acima, pode-se dizer que a disciplina voltada ao corpo e a regulação da sociedade ligada ao conjunto de seres humanos ou à biopolítica são na verdade dois elementos em que se estabelece a organização do poder sobre a vida ou sobre o biopoder em Foucault.

Byung-Chul Han (1959-) é um filósofo e teorista cultural Sul Coreano que ao se dedicar ao estudo do poder em contexto neoliberal, onde há uma desigualdade estrutural, identifica no domínio da informação e no discurso, elementos fundantes para a sua concepção do poder, entendida como uma estratégia política da sociabilidade e da comunicação.

Inspirando-se em Foucault, Han no seu pensamento sobre o poder pretende evitar a concepção coercitiva do poder, no sentido de ela ser uma luta de forças antagónicas ou de consensos, para uma percepção do poder como um agir comunicativo $\left(\right.$ Habermas $\left.^{4}\right)$. Por conseguinte, sua pretensão é encontrar um conceito que não põe de lado a sua ocorrência, tanto por via coercitiva como por via do consenso.

Han concebe o poder como um fenómeno complexo, no sentido de que ele implica de alguma forma certa reciprocidade entre aquele que o detém e os subordinados. Para Han, o poder se configura em diferentes formas de continuidade e mediação, nas quais a vontade do Ego pode-se expandir e continuar no Alter (HAN, 2019).

${ }^{4}$ Cfr. Para entender sobre o Agir Comunicativo pode-se consultar a seguinte obra: HABERMAS, J. (2012). Teoria do Agir Comunicativo. Tradução: Paulo Astor Soethe. São Paulo: Martins Fontes. 
Assim sendo, para melhor explicitar a complexidade do conceito poder, Han escreve a obra "O que é Poder", desdobrando-a em 5 dimensões: a lógica, a semântica, a metafísica, a política e a ética do poder. Sem pretender entrar em detalhes, em linhas gerais nesta obra, pode-se inferir que ela apresenta de forma pedagógica, um estudo a ser tomado em conta quando se pretender fazer uma análise das sociedades atuais no concernente à problemática do poder.

Neste diapasão, o poder cria continuidade, pois, "o poder é um fenómeno de continuidade" (Han, 2019, p.11). Em outras palavras, para Han, se o poder não cria continuidade, quer dizer, se não for-além-de-si, e depois retornar-a-si, - ele não existe, posto que, a continuidade assim percebida constitui a génese das estruturas do poder, portanto, a própria génese do poder.

\section{Dessa forma, Han compreende o poder como um}

fenômeno demasiadamente complexo e, nesse sentido, para ter uma compreensão que não falte com algum modo de representação ou de aparição do poder, pretende formular um conceito móvel, capaz de adaptar-se a qualquer estrutura de poder possível. Podemos dizer que definir o campo de atuação do poder, separando-o expressamente da violência, é um dos desafios que Han se propôs ao desenvolver sua tese (SILVA, 2019, p. 199).

O poder existe numa relação de continuidade entre o Ego e o Alter, no sentido de que há uma correlação entre o Ego e o Alter, para existir o poder. Como na relação de conhecimento (Kant), não existe continuidade do Ego, sem o Alter, como ele atesta, ao denotar que,

o poder permite ao ego ser no outro por si mesmo. Ele gera uma continuidade do self. O ego realiza no alter suas decisões. É desse modo que o ego continua no alter. O poder proporciona ao ego espaços que são seus, nos quais, apesar da presença do outro, ele pode estar em si mesmo (HAN, 2019, p. 11).

Por conseguinte, o Ego, com vista a alcançar o poder, não pode agir sem tomar em conta o Alter, posto que, ao ignorá-lo, perderá o domínio do poder. Neste caso, pode-se tirar a ilação de que o poder em Han depende irrevogavelmente desta correlação de continuidade entre o Ego e o Alter.

Assim, o poder é esta capacidade de ir-além-de-si, continuando junto de si, como afirma, Han (2019, p. 49) que "Ir-além-de-si é a característica principal do poder [...] Ir-além-de-si é, e isso é o modo de caminhar do poder, ao mesmo tempo ir-junto-de-si. Essa unidade de além-de-si e junto-de-si aumenta o espaço do self'.

Ao lado da continuidade está a mediação comunicativa como elemento fundamental para o funcionamento do poder, no sentido de que sem ela, o poder se converte em violência. Logo, a mediação é o elemento essencial que faz com que o Alter aceite a vontade do Ego.

Em suma, há uma relação possível entre a concepção do poder formulada por Michel Foucault e ByungChul Han, no sentido de que ambos partem de uma relação específica do poder para daí criarem suas ilações, quer dizer Foucault parte de uma relação assimétrica e bipolar do poder que preconiza por um lado a autoridade e por outro lado a obediência e Han, duma relação de continuidade do poder que tem a propensão de se expandir além de si, portanto no outro. 


\section{Semelhanças e dissemelhanças entre a concepção de poder em Michel Foucault e Byung-Chul Han: uma articulação necessária}

Estudos existem que opõem por completo o pensamento de Foucault e Han, no entanto, em relação ao ponto em análise neste artigo, isto é, sobre a compreensão da complexidade do poder local, a oposição é tênue, posto que existem posições políticas adversas relativamente à manutenção ou não do poder e/ou se essa relação e articulação do poder é ou não necessária, pois Foucault parte de uma concepção relacional do poder e Han a partir da concepção da continuidade e mediação do poder entre o Ego e o Alter.

Os dois teóricos partem de uma concepção específica do poder para depois tirarem as suas ilações. Neste sentido, diferentemente de Foucault, Han concebe o poder como uma forma de continuidade em que o Ego encontra para se realizar no Alter sem nenhuma barreira possível, ou melhor, o poder em Han não encontra algo que lhe resista.

Considerando o poder nessa perspectiva, Han, se diferencia de Foucault, uma vez que este acredita que, onde há poder, há também forças de resistência. Ao contrário, Han atesta que é possível que exista poder sem que encontre resistência, porém, teria que ocorrer com uma continuidade ilimitada, posto que, um poder sem resistência denota uma estabilidade que se alcançou por certo domínio.

Deste modo, para Han (2019), o poder que pretende alcançar um espaço grande de domínio precisa atuar através da criação de um horizonte de sentido. Portanto, pode-se compreender no pensamento de Han que o poder não é apenas negativo, mas igualmente positivo. Então, o poder, mesmo na sua eloquência, não está determinado a negar o outro, mas a afirmar de si no outro.

Neste sentido, "o Ego e o Alter são copartícipes da estrutura do poder. O poder retira do Alter não o seu não amedrontado, mas o seu sim entusiástico, cheio de excitação e subserviência" (Silva, 2019, p. 201). Assim, considerado a concepção do poder acima explicado, pode-se inferir que em Han, o poder não apenas destrói, mas "deixa viver" (HAN, 2019).

Nesta colação de argumentos, pode-se deduzir que ao lado desta continuidade ilimitada está a mediação que, ao transformar a vontade do detentor do poder na vontade do subordinado, gera liberdade. Neste sentido, se a medição entre o Ego e o Alter for maior, todos e de igual forma usufruem desta liberdade. Entretanto, se a mediação for menor, saturada fica a liberdade gerada por esta mediação.

Foucault ao considerar o poder como relação, então toma o poder disciplinar como um poder normativo que leva o indivíduo a seguir um conjunto de regras e normas que o levam a um ato de obediência, que considera a biopolítica como técnica da governança da sociedade.

Consequentemente, em Foucault conceber o poder como relação, de certa forma

implica afirmar sua existência exclusivamente como ato, daí a afirmação de que o poder se exerce, é operatório, em detrimento do suposto que se possa tê-lo, de que seja uma propriedade. Mas é preciso ainda destacar a ideia igualmente singular de que o poder é produtivo, ideia que traz um aporte de positividade ao poder que não se concebia antes de Foucault. Dizer que o poder é produtivo é situá-lo no campo da construção social da realidade. De maior importância, como visto antes, temos o fato do poder constrói as múltiplas possibilidades e condições de sermos sujeitos. De maneira geral as relações de poder, como concebidas por Foucault, não são marcadas pela negatividade, ou recortadas por valores (SANTOS, 2016, p. 270). 
Neste caso, a existência de poder tanto em Foucault como em Han implica de forma concomitante, a existência da liberdade. Apesar de Han ser menos rigoroso sobre a relação entre poder e liberdade, Foucault ao falar desta relação, a compara com a escravidão, que nega qualquer possibilidade de liberdade, que de facto, não constitui per si uma relação de poder.

Contudo, em Foucault, o que determina as relações do poder instáveis, móveis e reversíveis é o fato de que elas se permeiam pelo ideal da liberdade. Nesta senda, há de fato, relações do poder, se os sujeitos implicados nesta relação forem livres, quer dizer "para que se exerça uma relação de poder, é preciso que haja sempre, dos dois lados, pelo menos uma certa forma de liberdade" (FOUCAULT, 2006, p. 276).

É deste argumento que Foucault ressalta no seu pensamento ao afirmar que a relação entre poder e liberdade é essencial para se perceber o diferencial entre o poder como relação de forças e a liberdade como capacidade de poder se orientar não dependendo dos outros para guiar a sua conduta (dominação).

Contrariamente a Foucault, Han nesta perspectiva denota que a existência de uma liberdade ainda que mínima permite que exista poder, ainda que escasso. Neste sentido,

a possibilidade de o escravo dizer "não" à vontade do poderoso é um modo de liberdade. Mesmo que pequeno esse "não" interrompe a mediação do poder entre ego e alter. Por isso mesmo, o poder é caracterizado não pelo seu não, mas pela possibilidade do sim. Pouca mediação desdobra-se em coerção, nenhuma mediação em violência. A violência, diferentemente do poder, quebra a continuidade do self, destrói o alter, isola o ego. A violência não é poder, pois aniquila o outro, encerra com os espaços de ação política (SILVA, 2019, p. 203).

Dessa forma, há por um lado alguns elementos em comum na concepção do poder em Foucault e em Han, e por outro lado, elementos divergentes na mesma concepção do poder como apontado acima. O que fica como ilação é que em Han o poder é considerado como uma forma de continuidade e mediação entre o Ego e o Alter, sem que exista uma resistência possível entre ambos, em detrimento de Foucault que definitivamente afirma que onde há poder há também forças de resistência.

Enquanto Foucault afirma que a sociedade contemporânea é feita de prisões, hospitais, fábricas constituindo, portanto, uma sociedade disciplinar, Han, atesta que estes elementos não são um reflexo da sociedade contemporânea, posto que, a sociedade disciplinar concebida por Foucault concorreu para o surgimento de uma sociedade de rendimento.

Em Han, ao contrário do sujeito de obediência caracterizado por Foucault, hoje em dia encontramos o sujeito de rendimento que é livre, quer dizer, a existência deste sujeito é regida pela liberdade e pela iniciativa, apesar de algumas vezes esta liberdade se transformar em coação e/ou em auto exploração (HAN, 2016).

Em síntese, existe sim uma articulação necessária entre as concepções de poder pensadas por estes dois teóricos, quer dizer, o pensamento de Foucault e Han se assemelha relativamente ao tema da liberdade, uma vez que ambos acreditam que nas relações do poder existe a liberdade, considerada como capacidade que os indivíduos têm de orientar as suas condutas dentro da relação de poder, sem esperar que alguém oriente a sua conduta. Portanto, por um lado, o poder é concebido como um fenômeno de continuidade (Han) e, por outro lado, o poder é pensado numa relação assimétrica bipolar (Foucault). 


\section{A contribuição do pensamento de Michel Foucault e Byung-Chul Han nas teorias atuais do poder}

A abordagem moderna do poder é marcada por uma antipatia em vários países no concernente aos modos de sua efetivação, principalmente nas democracias representativas, apesar de este modelo não ter tido superação nas práticas políticas. Destarte, Foucault e Han são entre os vários teóricos, que contribuíram sobremaneira para a abordagem do poder sob ponto de vista empírico.

Os modelos ideais da percepção do poder e espaço social hoje em dia são efetuados, por meio de diversas instituições que procuram aplicar o poder não de forma relacional, mas aliado à dominação (Weber, 2016), à hegemonia (Gramsci, 1982), (Laclau; Mouffe, 1987) e ao poder simbólico (Bourdieu, 2001).

Falar da contribuição do pensamento de Foucault e Han, e em especial, abordar neles a concepção do poder é um quesito essencial para a compreensão não só da democracia moderna, como também do Estado moderno. Por conseguinte, é analisando o pensamento político relativo ao poder destes teóricos que se percebe como as instituições e o Estado deixaram seu caráter natural, assumindo deste modo a sua personalidade civil, através da formação do contrato social.

Contudo, no Estado moderno, os indivíduos são considerados como detentores de direitos e deveres, isto é, são considerados como cidadãos, e é com base nessa formação que, no atual século, o Homem dentro do Estado é conditio sine qua non para a garantia da justiça e de direitos.

No pensamento de Foucault considera-se o poder não situado em nenhuma instituição muito menos como algo que cede através de contratos tanto políticos como jurídicos. Em boa verdade, o poder para ele não só reprime como também produz efeitos de saber e verdade.

Estas ilações fazem com que Foucault através da sua teoria do poder relacional seja considerado como um teórico que contribuiu e contribui sobremaneira para o debate sobre a problemática do poder, que é considerado disciplinar, no sentido de que as relações do poder são dadas pelas instituições como escolas, fábricas, prisões, quartéis que ao longo do tempo foram marcadas pela disciplina. Assim, tomando o poder como relacional, Foucault o pensa numa ideia de força, posto que as relações do poder devam considerar como ponto de partida as formas de resistência contra as diferentes formas de poder.

Como atesta Deleuze (2008, p. 112) para secundar esta ideia de força,

o poder é precisamente o elemento informal que passa entre as formas de saber, ou por baixo delas. Por isso ele é dito microfísico. Ele é força, e relação de força, não forma. E a concepção das relações de forças em Foucault, prolongando até Nietzsche, é um dos pontos mais importantes de seu pensamento.

Por outro lado, o pensamento de Han também é essencial na formação, constituição e consolidação das teorias atuais do poder, uma vez que ele concebe o poder como um fenómeno complexo. À vista disto, Han, considerando o poder como um fenómeno que na sua compreensão não deva faltar com algum modo da sua representação, ele defende um conceito móvel, dinâmico de poder passível de se adaptar à qualquer estrutura do poder possível. 
Como o poder para Han é um fenômeno complexo, ele prefere considerar o poder como continuidade e como mediação comunicativa, no sentido de que sem a mediação ele constituiria violência, e portanto, a mediação é precisamente para ele, o que difere da atuação do poder do fenômeno da violência. Destarte, é a mediação que permite com que o Alter aceite subservientemente a vontade do Ego.

Por conseguinte, o pensamento destes dois teóricos é essencial não só para a formação, constituição e consolidação das atuais teorias do poder, como também para fundamentação das democracias representativas atuais e/ou para a compreensão da complexidade do poder local, no caso específico de Moçambique. Foucault pensa o poder não só como agenciamento no campo político, quer dizer, não só como um espaço onde se imprimem as experiências históricas de lutas sociais, mas também como desdobramento no campo ético, isto é, como uma liberdade que subjaz entre a autonomia e maioridade.

Em suma, Han, ao conceber o poder, portanto, como relação entre o Ego e o Alter, afirma que o poder é a capacidade, continuidade de prolongar a própria vontade na vontade dos outros, tornando o poder como fenómeno complexo. Estes elementos concorrem para a percepção de quão importante foi o pensamento de Foucault e Han não só para a formação e constituição das atuais teorias de poder, como também para compreender a complexidade do poder local no Estado moderno que se presa democrático.

\section{A relevância das concepções de poder em Michel Foucault e Byung-Chul Han na compreensão da complexidade do poder local em Moçambique}

Moçambique é um país unitário, democrático e descentralizado e se situa na costa sudeste do continente africano com uma dimensão territorial de aproximadamente $800.000 \mathrm{Km}^{2}$ e com uma população de aproximadamente 30 milhões de habitantes.

O poder local em Moçambique constitui uma realidade complexa no sentido de que este tipo de poder existe antes do surgimento do Estado moderno per si. Desse modo, antes da chegada dos Portugueses (1498), Moçambique era habitado por comunidades organizadas, e era gerido por unidades políticas, sobretudo reinos (Monomotapa e os centros Swahilis) dirigidos por um soberano, de acordo com um sistema de filiação ou de linhagem cuja origem do poder se assentava nos antepassados, num desígnio sobrenatural (UEM, 1982).

Ao mesmo tempo existiam outras unidades políticas mais simples, que se organizavam como um conjunto de comunidades que se ligavam através do parentesco ou por um antepassado comum mítico, sem nenhum poder centralizador e deveras com instituições políticas muito simples.

Uma primeira chave analítica da complexidade do poder local está ligado à própria ideia do poder local, quer dizer, à sua importância principalmente no contexto democrático, ou mesmo à sua complexidade intrínseca, que nesta análise, não se resume a uma problemática menor, e a um simples funcionamento do poder em pequena escala.

No contexto africano e em especial, em Moçambique o poder local é um dos veículos privilegiados na compreensão do fenômeno político na sua complexidade, se considerar a noção do poder enquanto algo construído no quadro das relações sociais entre agentes, concepção próxima à noção de poder em Michel 
Foucault e em Byung-Chul Han. Neste sentido, as noções de Foucault e Han são relevantes na compreensão da complexidade do poder local em Moçambique.

A bem dizer, o poder local significa "a necessidade que as populações de um determinado território têm, de se auto administrarem e gerirem autonomamente, os seus interesses próprios e comuns" (Zavale, 2011, p. 35). Neste sentido, a criação do poder local em Moçambique foi um meio de que o país se serviu na tentativa de descentralizar o poder e desenvolver a democracia, ao envolver as populações na tomada de decisões da vida pública, contudo, na prática muitas das vezes estes espaços servem como locais de reprodução das elites do próprio governo central.

Numa leitura crítica desses espaços formais, Bilério avalia que estas instituições "parecem ser mais espaços de reprodução de elites ao nível local e de manipulação da população a avaliar pela sua constituição (seleção dos membros) e seu funcionamento e não espaços de participação da população no processo de tomada de decisões" (BILÉRIO, 2018, p. 64).

Neste sentido, hoje em dia existem conflitos entre os diferentes grupos sociais representados nos poderes locais, por causa da sua incompleta aplicação, e afeta sobremaneira, o arranjo do poder político em diferentes grupos da sociedade local.

Com isto, pode-se inferir que o pensamento de Michel Foucault é essencial na compreensão da complexidade do poder local em Moçambique, ao considerar o poder como uma relação entre a autoridade, e neste caso a autoridade tradicional, e a obediência, que seria, assim, a sociedade no geral. A sociedade, no caso moçambicano deve obediência às autoridades tradicionais e subordina-se a elas com vista a garantir a ordem social, aliás, a autoridade tradicional, os conselhos consultivos, são os garantes da ordem pública e social.

Byung-Chul Han, ao conceber o poder como fenômeno complexo, de continuidade e de mediação comunicativa também é essencial para a compreensão da complexidade do poder local em Moçambique, no sentido de que existe uma semelhança na sua concepção do poder e naquilo que acontece na realidade moçambicana. Para Han, o poder ao implicar uma certa forma de reciprocidade entre os detentores do poder, que seriam para o caso moçambicano, as autoridades tradicionais e os conselhos consultivos, e os subordinados, então o poder, neste caso, constitui uma continuidade que se expande desde a vontade das autoridades tradicionais até à sociedade como um todo.

Estes aspetos concorrem para perceber quão importante é o pensamento de Foucault e Han, na compreensão da complexidade do poder local, não só no caso moçambicano, como no mundo em geral. A atual configuração constitucional moçambicana não fala de poderes locais, mas sim de autarquias locais, no sentido de que ambos conceitos são considerados como sinônimos. Aliás, a constituição de 2004 já previa no seu artigo 271, que o

Poder Local tem como objetivos organizar a participação dos cidadãos na solução dos problemas próprios da sua comunidade e promover o desenvolvimento local, o aprofundamento e a consolidação da democracia, no quadro da unidade do Estado Moçambicano, e na iniciativa e na capacidade das populações e atua em estreita colaboração com as organizações de participação dos cidadãos (números 1 e 2 do artigo 271 da Constituição de 2004). 
Contudo, a Constituição da República de 2004, com as alterações sofridas pela lei 1/2018 de 12 de junho ${ }^{5}$, usa simplesmente o conceito de Autarquias Locais no lugar de Poderes Locais, mantendo a definição e objetivos feitos para aquele conceito.

Sendo assim, o Poder Local pode ser definido neste contexto em duas vertentes. Do de vista teórico, o Poder Local é aquele que nasce num local, o poder que emana do povo e não um poder imposto no local. Neste sentido, o Estado não é poder local, é um poder imposto no local. Do de vista prático, o Poder Local é a representação do Estado no local, como é o caso dos municípios e dos serviços ministeriais (POULSON, 2009; FAURÉ \& RODRIGUES, 2012).

Os estudos de Wunsch \& Olowu (2005) ao referirem sobre a instituição dos poderes locais na África, aduzem que constituem um processo através do qual os residentes de uma determinada área participam na resolução de seus problemas locais. Eles são os decisores-chave na escolha de prioridades de projetos locais, sua implantação e da forma como os recursos são alocados para o sucesso desses mesmos projetos.

Os estudos empíricos de Forquilha (2009) sobre a aplicação dos poderes locais em Moçambique concebem-nos como uma forma de governação onde vários atores estatais e extras estatais, singulares e coletivos participam da provisão de bens e serviços.

Em Moçambique, o poder local é anterior ao Estado como se afirmou e que muitas das vezes pode-se desenvolver fora dele. Assim, existem poderes locais paralelos, como o poder tradicional que surgiu como uma manifestação do poder local. Ao lado do poder tradicional, no local existe a participação democrática das populações nas comissões dos bairros, através dos Conselhos Consultivos Locais. Esta constatação leva à ilação de que os poderes locais estão além das autarquias, no sentido de que são eles que garantem a satisfação dos interesses das respetivas populações, principalmente no meio rural onde não existe a presença do Estado.

No caso moçambicano, os detentores do poder tradicional possuem uma autoridade legítima conferida pelas regras de convivência que se assentam no direito consuetudinário. Consequentemente, as autoridades tradicionais possuem um poder legitimado pelas comunidades, enquanto detentores de conhecimentos sobre as tradições locais e enquanto gestores das relações políticas estabelecidas no seio dessas comunidades rurais.

No caso moçambicano, são Autoridades Comunitárias, em conformidade com o número 1 do artigo 1 do decreto 15/2000 de 20 de junho ${ }^{6}$, "os chefes tradicionais, os secretários dos bairros ou de aldeias e outros líderes legitimados como tais pelas respectivas comunidades locais". As autoridades tradicionais, os líderes comunitários, os líderes religiosos e os régulos foram durante muito tempo figuras que faziam uma interface entre o governo central e as comunidades e entre as comunidades e os antepassados. Estes poderes concorrem para a percepção de que o poder local é complexo em Moçambique e muitas das vezes há querelas de legitimidade de cada poder no local.

\footnotetext{
${ }^{5}$ Lei da Revisão Pontual da Constituição da República de Moçambique.

${ }^{6}$ Decreto do Conselho de Ministros que estabelece as formas de articulação dos órgãos locais do Estado com as Autoridades Comunitárias.
} 
Muitas destas autoridades se afirmaram e ainda hoje em dia se afirmam como autoridades locais junto das comunidades, posto que, nem sempre o Estado esteve presente ou representado junto delas. Dessa forma, uma vez existindo um espaço vazio deixado pela ausência ou incapacidade do poder estatal de se afirmar junto delas, este espaço foi e ainda é ocupado pelos chefes tradicionais, líderes comunitários, líderes religiosos, secretários de bairro ou de aldeia, entre outros.

Formalmente, os Conselhos Consultivos Locais são espaços de consulta onde a população, através dos seus representantes ao nível local deveriam influenciar o governo a tomar as decisões a seu favor. Os Conselhos Consultivos Locais foram uma iniciativa do governo central para responder aos interesses locais do Estado e da comunidade onde eles se localizam, constituindo-se como um fórum de caráter consultivo e informativo sem poder legislativo e nem coercivo no seio da respetiva comunidade (JAMAL, 2014).

A posição do poder local na pessoa das autoridades tradicionais, líderes comunitários, líderes religiosos, secretários dos bairros ou de aldeias, como intermediários na ligação com o Estado é aparentemente a sua mais forte marca do poder local em Moçambique, no sentido de que, são entidades que foram assumindo um papel a meio caminho entre o central e o local.

Atualmente, as autoridades tradicionais, os líderes comunitários, os líderes religiosos, os secretários dos bairros ou de aldeias, que constituem neste caso, poderes locais, são na realidade agentes locais organizados, intermediários cujo perfil é muitas vezes atípico. Estão a ser reconhecidos como agentes eficazes na articulação entre o nível central e o local, tornando o poder local em Moçambique complexo.

De qualquer modo, baseados numa tradição que se assenta em fatores de hereditariedade, as autoridades tradicionais, os líderes comunitários, os líderes religiosos, os secretários dos bairros ou de aldeias, portanto, os poderes locais, têm agora a sua existência reconhecida pela Constituição. Contudo, o que será efetivamente o seu papel, ficará consignado nos instrumentos reguladores do exercício da sua atividade. Estes elementos na verdade concorrem para a percepção de quão complexa é a compreensão do poder local em Moçambique, sob ponto de vista de análise deste artigo.

Em síntese, analisando a concepção de Michel Foucault e Byung-Chul Han sobre poder denota-se que o poder é uma realidade social e complexa que é essencial para a existência de uma sociedade. A bem dizer, o poder local em Moçambique constitui um fenômeno no âmbito do poder político que possui na sua base, o princípio da descentralização político-Administrativo. Estes elementos concorrem para a percepção de que de facto, as concepções de Foucault e Han são muito importantes na compreensão da complexidade do poder local, não somente em Moçambique como também em todo o mundo.

\section{Considerações finais}

Este artigo infere que tanto Michel Foucault como Byung-Chul Han, em todas as suas obras, apesar da questão do poder não ter sido o seu objeto especial de estudo, todos de alguma forma conceberam uma noção de poder.

Tomando em consideração as acepções do poder aqui apresentadas, pode-se concluir que em Michel Foucault o poder é uma construção social que se encontra em toda a parte. Provoca de certa forma uma relação 
assimétrica, não se encontrando em nenhuma instituição muito menos em ninguém, mas sim nas relações sociais. Destarte, para que o poder em Foucault seja eficaz é preciso que produza uma positividade que de certa forma se desdobre na vida social, cujo preço é o adestramento do corpo, quer dizer, o poder disciplinar.

Byung-Chul Han afirma que o poder é um fenômeno demasiadamente complexo que só existe numa relação de continuidade e de mediação entre o Ego e o Alter, que ambos devem transformar o Não em Sim. Neste caso, o poder assim concebido em Han consiste na capacidade que o Ego tem, de prolongar a sua própria vontade em vontade dos outros, fazendo com que o poder seja concebido como liberdade com um carácter comunicativo.

Concebidas estas considerações sobre o poder em Michel Foucault e em Byung-Chul Han, as reflexões por eles propostas contribuem não como proposições teóricas e acabadas sobre o poder, mas como referenciais para uma compreensão crítica e dinâmica da complexidade do poder local, sem a qual sequer seria possível, no contexto da sociedade hodierna, sua identificação como tal.

Em suma, esta pesquisa infere que tanto Michel Foucault como Byung-Chul Han, conceberam certo tipo de poder, que foi importante não só para a formação e constituição das atuais teorias de poder, como também para compreender quão complexa é a concepção do poder local no Estado moderno, e em especial em Moçambique.

\section{Referências}

ALBUQUERQUE, J. A. G. Michel Foucault e a Teoria do Poder. Tempo Social: Rev. Sociol. USP, v. 7, n. 12, p. 105-110, out., 1995.

ARENDT, H. A Condição Humana. Tradução Roberto Raposo, revisão técnica Adriano Correia. 11 ed. Rio de Janeiro: Forense Universitária, 2010.

BILÉRIO, B. E. Dinâmica da Accountability no Contexto da Governança Local em Moçambique entre 1998 2016: Um Estudo dos Municípios da Matola e Beira. 2018. 198f. Tese (Doutorado em Ciência Política) Instituto de Estudos Sociais e Políticos, Universidade do Estado do Rio de Janeiro, Rio de Janeiro, 2018.

BOLETIM DA REPÚBLICA. Decreto n 15/2000, de 20 de junho. Estabelece as formas de articulação dos Órgãos Locais do Estado com as autoridades comunitárias. Suplemento, I Série-Número 24. Imprensa Nacional: Maputo, 2000.

BOLETIM DA REPÚBLICA. Constituição da República de Moçambique, de 22 de dezembro de 2004. I Série, Número 51. Imprensa Nacional: Maputo, 2004.

BOLETIM DA REPÚBLICA. Lei no 1/2018 de 12 de junho de 2018. Lei da Revisão Pontual da Constituição da República de Moçambique. I Série, Número 115. Imprensa Nacional: Maputo, 2018.

BOURDIEU, P. O Poder Simbólico. Rio de Janeiro: Bertrand Brasil, 2001.

DELEUZE, G. Conversações. São Paulo: Ed. 34, 2008.

DREYFUS, H. \& RABINOW, P. Michel Foucault, uma trajetória filosófica: para além do estruturalismo e da hermenêutica. Tradução de Vera Porto Carrero. Rio de Janeiro: Forense Universitária, 1995.

FAURÉ, Y. A. \& RODRIGUES, C. U. Descentralização e Desenvolvimento Local em Angola e Moçambique: Processos, Terrenos e Atores. Lisboa: Edições Almedina, 2012. 
FORQUILHA, S. C. O Paradoxo da Articulação dos Órgãos Locais do Estado com as Autoridades Comunitárias em Moçambique: Do discurso sobre a descentralização à conquista dos espaços políticos a nível local, Cadernos de Estudos Africanos [Online], n. 16/17, 2009.

FOUCAULT, M. A Ética do Cuidado de si como Prática da Liberdade. In: MOTTA, Manoel Barros da. Foucault: Ética, Sexualidade, Política: Rio de Janeiro: Forense, 2006.

FOUCAULT, M. História da Sexualidade 1. A Vontade de saber. Rio de Janeiro: Graal, 2010.

FOUCAULT, M. Microfísica do Poder. Tradução e organização de Roberto Machado. 13 ed. Rio de Janeiro: Graal, 1998.

FOUCAULT, M. Soberania e Disciplina. Curso do Collège de France, 14 de janeiro de 1976. In: Microfísica do Poder. Rio de Janeiro: Graal, 1979.

FOUCAULT, M. Vigiar e Punir: Nascimento da Prisão. Tradução de Raquel Ramalhete. 42 ed. Petrópolis, RJ: Vozes, 2014.

GRAMSCI, A. Os Intelectuais da Cultura. 4 ed. Rio de Janeiro: Civilização Brasileira, 1982.

HABERMAS, J. O conceito de poder de Hannah Arendt (1976). In: Freitag, B. e Rouanet, S. P. (Orgs.). Habermas: São Paulo: Ática, 1980.

HAN, Byung-Chul. O que é Poder? Tradução de Gabriel Salvi Philipson. Petrópolis: Vozes, 2019.

HAN, Byung-Chul. Topología de la Violencia. Tradução Paula Kuffer. Barcelona: Herder, 2016.

JAMAL, S. Descentralização e democracia local: mecanismos de participação e prestação vertical de contas dos governos locais em Moçambique - Os Conselhos Consultivos Locais. 2014. $85 f$.

Dissertação (Mestrado em Roads to Democracies - Democracia e Governação) - Faculdade de Economia, Universidade de Coimbra. Coimbra, 2014.

LACLAU, E; MOUFFE, C. Hegemonia y Estratégia Socialista. Hacia uma Radicalización de la Democracia. Madrid: Siglo XXI, 1987.

POULSON, L. As Autarquias Locais e as Autoridades Tradicionais no Direito Angolano: esboço de uma teoria subjectiva do poder local. Luanda: Casa das ideias, 2009.

REVEL, J. Michel Foucault: Conceitos Essenciais. São Carlos: Claraluz, 2005.

SANTOS, P. R. A Concepção de Poder em Michel Foucault. Especiaria - Cadernos de Ciências Humanas. v. 16, n. 28, jan./jun. p. 261-280, 2016.

SILVA, D. O. A Continuidade como Conceito do Poder. Revista Eletrônica de Humanidades do Curso de Ciências Sociais da UNIFAP, v. 12, n. 1, p. 199-204, jan./jun, 2019.

SOUZA, W. L. Ensaio sobre a Noção de Poder em Michel Foucault. Revista Múltiplas Leituras, v. 4, n. 2, 2011, 2011.

Universidade Eduardo Mondlane (UEM). Departamento de História. História de Moçambique Volume 1: Primeiras Sociedades Sedentárias e Impacto dos Mercadores, Maputo: Cadernos TEMPO, 1982.

WEBER, M. Economia e Sociedade. Brasília/ São Paulo: Editora da Universidade de Brasília, Editora UnB/Imprensa Oficial do Estado de São Paulo, 2004.

WEBER, M. Os Três Tipos Puros de Dominação Legítima. In: Metodologia das Ciências Sociais: São Paulo/Campinas: Cortez/Ed. da UNICAMP, 2016. 
WUNSCH, J. \& OLOWU, D. Local Governance in Africa. The Challenges of Democratic Decentralization. Boulder and Londres, Lynne Rienner Publishers, 2005.

ZAVALE, G. J. B. Municipalismo e Poder Local em Moçambique. Maputo: Escolar Editora, 2011. 